\title{
Sulindac induced regression of colorectal adenomas in familial adenomatous polyposis: evaluation of predictive factors
}

F M Giardiello, J A Offerhaus, A C Tersmette, L M Hylind, A J Krush, J D Brensinger, S V Booker, S R Hamilton

\begin{abstract}
Background-Sulindac, a non-steroidal anti-inflammatory drug, causes regression of colorectal adenomas in patients with familial adenomatous polyposis (FAP) but the response is variable. Specific clinical factors predictive of sulindac induced regression have not been studied.

Methods-22 patients with FAP were given sulindac $150 \mathrm{mg}$ orally twice a day. Polyp number and size were determined before treatment and at three months. The relation of nine clinical factors to polyp regression (per cent of baseline polyp number after treatment) was evaluated by univariate and multivariate analysis.
\end{abstract}

Results-After three months of sulindac, polyp number had decreased to 45 per cent of baseline and polyp size to 50 per cent of baseline $(p<0.001$ and $p<0.01$, respectively). Univariate analysis showed greater polyp regression in older patients $(p=0.004)$, those with previous colectomy and ileorectal anastomosis $(p=0.001)$, and patients without identifiable mutation of the APC gene responsible for FAP $(p=0 \cdot 05)$. With multivariate regression analysis, response to sulindac treatment was associated with previous subtotal colectomy.

Conclusions-Sulindac treatment seems effective in producing regression of colorectal adenomas of FAP patients with previous subtotal colectomy regardless of baseline polyp number and size. Changed sulindac metabolism, reduced area of the target mucosa, or changed epithelial characteristics after ileorectal anastomosis may explain these findings.

(Gut 1996; 38: 578-581)

Keywords: sulindac, colorectal adenomas, familial adenomatous polyposis.

Departments of Pathology and Clinical Epidemiology,

Academic Medical

Centre, Amsterdam,

the Netherlands

J A Offerhaus

A C Tersmette

Correspondence to:

Dr F M Giardiello, Blalock 935, The Johns Hopkins Hospital, $600 \mathrm{~N}$ Wolfe

Street, Baltimore, Maryland

21287, USA

Accepted for publication

9 October 1995 inflammatory drug (NSAID) pharmacologically and structurally related to indomethacin. Sulindac inhibits prostaglandin synthesis by inhibition of cyclooxygenase, the enzyme that catalyses the formation of prostaglandin precursors from arachidonic acid. ${ }^{1}$ This agent exhibits anti-inflammatory, analgesic, and antipyretic activity like other NSAIDs and has similar side effects. Sulindac, a prescription drug used clinically since the mid-1970s, is indicated for the treatment of patients with acute and chronic rheumatological disorders.

In 1983, Waddell et $a l^{2}$ first reported that sulindac caused regression of rectal adenomatous polyps in several patients with familial adenomatous polyposis (FAP), an inherited form of colorectal cancer caused by germline mutation of the APC gene on the long arm of chromosome $5 .{ }^{34}$ Over the past decade, this initial report has been confirmed by numerous anecdotal publications as well as three controlled trials of sulindac in patients with FAP, ${ }^{5-7}$ although the mechanism of adenoma regression through prostaglandin inhibition remains unclear. ${ }^{8}$ In our previous randomised, double blinded, placebo controlled study of patients with FAP, a statistically significant decrease in mean polyp number and size occurred in patients treated with sulindac compared with placebo at three, six, and nine months. ${ }^{6}$ The completeness of regression, however, was variable and no patient showed total regression of polyps. The purpose of this study was to evaluate by univariate and multivariate analysis the role of several clinical factors as possible predictors of sulindac effect on regression of colorectal adenomas in patients with FAP.

\section{Methods}

Subjects

Data on 22 FAP patients treated with sulindac for colorectal polyp regression were reviewed from clinical records. Eleven patients treated with sulindac in our previous study were included. ${ }^{6}$ Subjects were recruited from The Johns Hopkins Polyposis Registry. Inclusion criteria were FAP patients who had not undergone colectomy or who had undergone subtotal colectomy with ileorectal anastomosis and had five or more rectal adenomas. Exclusion criteria were use of NSAIDs for more than one week during the previous three months, absence of effective birth control in women of child bearing age, pregnancy, white blood cell count $<4000 / \mathrm{ml}$, platelet count $<100000 / \mathrm{ml}$, blood urea nitrogen $>25 \mathrm{mg}$ per cent, or creatinine $>1.5 \mathrm{mg}$ per cent, refusal to discontinue NSAIDs, history of peptic ulcer disease or gastrointestinal haemorrhage, history of malignancy, active bacterial infection, use of dimethylsulphoxide, history of aspirin allergy. 
TABLE I Clinical features of study population

\begin{tabular}{lc}
\hline Characteristics & \\
\hline Patients (n) & 22 \\
Mean age (SD) (range) & $26 \cdot 4(11 \cdot 2)(13-52)$ \\
Sex (\%) & $13(59)$ \\
$\quad$ Female & $9(41)$ \\
$\quad$ Male & $73 \cdot 7(22 \cdot 3)(47-125)$ \\
Body weight (kg) (range) & $264(47 \cdot 1)(129-300)$ \\
Mean (SD) sulindac dose & \\
$\quad$ (mg/dayXcompliance) & $10(45)$ \\
Surgical status (\%) & $12(55)$ \\
$\quad$ Intact colon & $17(77)$ \\
$\quad$ Ileorectal anastomosis & $5(23)$ \\
APC gene mutation (\%) & $11(50)$ \\
$\quad$ Identified & $11(50)$ \\
Not found & Extracolonic lesions (\%) \\
$\quad$ Present & Absent \\
Mean (SD) number of polyps at & $28 \cdot 5(36 \cdot 1)(7-160)$ \\
$\quad$ baseline (range) & $3 \cdot 0(1 \cdot 2)(1 \cdot 5-6 \cdot 2)$ \\
Mean (SD) size of polyps (mm) at \\
baseline (range)
\end{tabular}

\section{Study design}

Rectosigmoid colonic polyps and rectal polyps were assessed by flexible sigmoidoscopy using an Olympus flexible video sigmoidoscope. ${ }^{6}$ One observer (FMG), without knowledge of previous examination results, performed all assessments. Examinations were done before sulindac administration (0 months) and at three months. At time 0 , the colorectal mucosa was tattooed with sterile Indian ink about 20 $\mathrm{cm}$ from the anal verge. The endoscopist counted the total number of polyps in the entire circumference of colorectum from the tattoo mark to the anal verge and recorded the examination on videotape. The size of each of the first five polyps just distal to the tattoo was measured with a graduated millimetre scale passed through the biopsy channel of the sigmoidoscope.

Each patient received sulindac $150 \mathrm{mg}$ orally twice a day for three months. Patient compliance was assessed by tablet counts and weekly telephone contact.

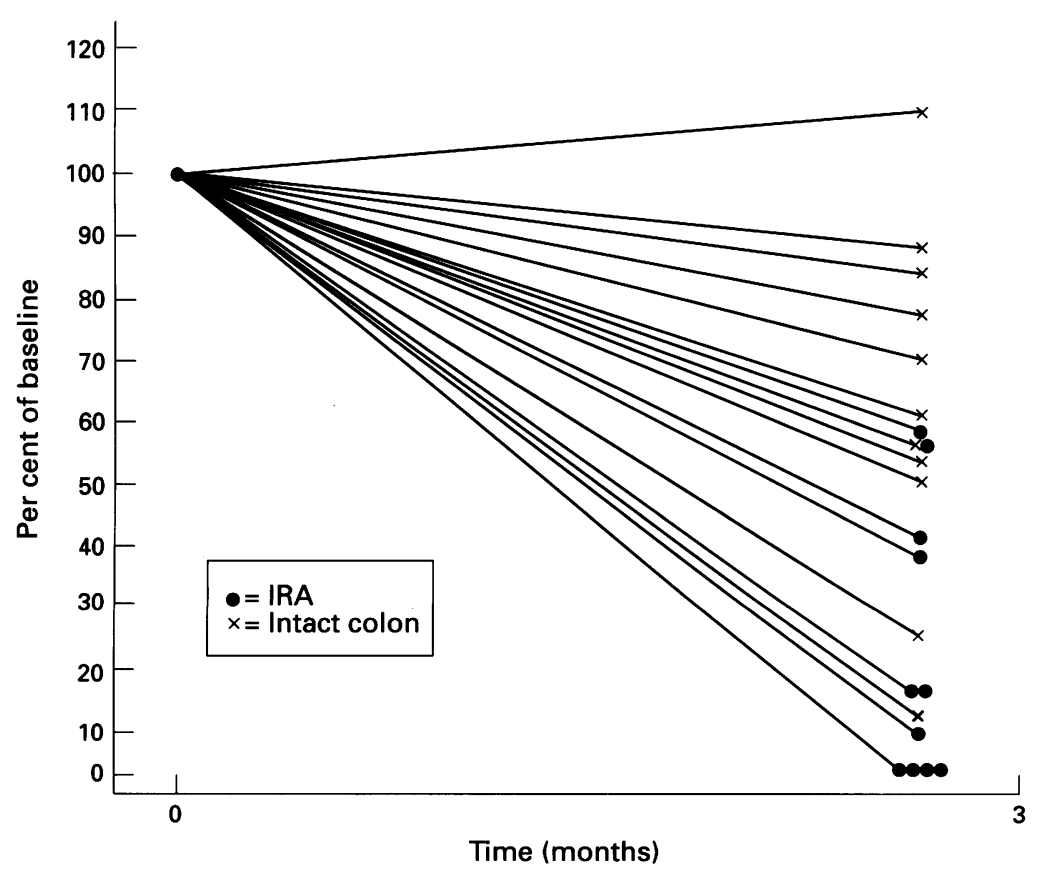

Polyp regression on sulindac expressed as per cent of baseline polyp number after three months of sulindac treatment in patients with intact colons or with previous ileorectal anastomosis (IRA). More complete regression occurred in patients with previous colectomy.
Dependent and independent variables

Per cent change from baseline number of polyps after treatment with sulindac for three months was evaluated with respect to nine clinical factors (Table I): age $(<v \geqslant 30$ years old); sex; body weight $(<v \geqslant 65 \mathrm{~kg})$; dose of sulindac (dose of sulindac prescribed $\times$ per cent of drug taken during the first three months per $\mathrm{kg} ;<v \geqslant 4.0 \mathrm{mg} / \mathrm{kg} /$ day); surgical status (subtotal colectomy or no prior colectomy); presence or absence of APC gene mutation as assessed by in vitro synthesised protein assay and by cloning and sequencing the entire coding region of the APC gene, as described previously ${ }^{9-11}$; presence or absence of extracolonic lesions (cutaneous cysts, osteomas, pigmented ocular fundus lesions, occult radioopaque jaw lesions, odontomas, extracolonic cancers and desmoids); number of polyps at baseline $(<v \geqslant 20$ polyps), and mean size of polyps at baseline $(<v \geqslant 3.0 \mathrm{~mm})$.

\section{Statistical analysis}

Polyp number and mean size were calculated before and after sulindac treatment, and differences were analysed for statistical significance by paired $t$ test. Regression was expressed as per cent of base line.

The relation between change in per cent of baseline polyp number at three months (dependent variable) and patient clinical features (independent variables) was evaluated by both univariate and multivariate analysis and tested for significance by a $t$ test. The contributions of independent variables found to have a significant impact on polyp regression by univariate analysis were evaluated by multiple regression analysis with per cent change from baseline number of polyps as the primary statistical outcome variable. Statistical significance was defined as $\mathrm{p}$ value $<0 \cdot 05$.

\section{Results}

Table I shows the baseline clinical features of the study population. After three months of sulindac, polyp number had decreased to 45 per cent of baseline (Figure) and polyp size to 50 per cent of baseline $(p<0.001$ and $p<0.01$, respectively).

Univariate analysis showed a significantly better polyp regression in older patients $(p=0.004)$, those with previous subtotal colectomy and ileorectal anastomosis $(p=0.001)$, and was borderline significant for patients without identified APC gene mutation $(p=0.05)$. With multivariate regression analysis, only previous surgery (patients with colectomy and ileorectal anastomosis) was associated with statistically significant better polyp regression (Table II). Analysis with polyp size as the dependent variable showed similar results (data not shown).

\section{Discussion}

Our finding of greater polyp regression in patients with retained rectum after subtotal colectomy compared with intact colon could 
TABLE II Results of multivariate analysis with polyp number of dependent variable

\begin{tabular}{|c|c|c|c|c|}
\hline Variables & Regression coefficient & $S E M$ & t Test & p Value \\
\hline Constant & $67 \cdot 3$ & $8 \cdot 128$ & $8 \cdot 280$ & 0.0000 \\
\hline Age & $-0 \cdot 2944$ & - & $-1 \cdot 360$ & 0.1898 \\
\hline Sex & -0.0608 & - & -0.354 & 0.727 \\
\hline Body weight & -0.1886 & - & $-1 \cdot 146$ & $0 \cdot 2660$ \\
\hline Sulindac dose & 0.1765 & - & 1.064 & 0.3008 \\
\hline Surgical status & $-44 \cdot 717$ & $11 \cdot 005$ & $-4 \cdot 063$ & 0.0006 \\
\hline Mutation status & 0.2506 & - & 1.500 & 0.1501 \\
\hline Extracolonic lesion status & $-0 \cdot 1258$ & - & -0.739 & 0.4691 \\
\hline Number of polyps at baseline & 0.0858 & - & 0.508 & 0.6171 \\
\hline Size of polyps at baseline & $0 \cdot 1437$ & - & 0.858 & $0 \cdot 4015$ \\
\hline
\end{tabular}

be explained by the metabolism of sulindac. After oral administration, sulindac is metabolised by oxidation of its sulphonyl substituent to sulphone and reduction to sulphide. ${ }^{12}$ Pharmacological investigations show that sulindac is a prodrug exerting no antiinflammatory activity; rather, its effect is solely attributed to its sulphide metabolite. ${ }^{13}$ Moreover, the sulphone and sulphide metabolites of sulindac inhibit rat colonic carcinogenesis $^{14}$ and growth of colorectal cancer cells in tissue culture. ${ }^{815}$ Because of extensive enterohepatic circulation and the reduction of sulindac to the active sulphide by colonic bacterial flora, ${ }^{16} 25 \%$ of a single sulindac dose is found in the faeces as sulphone and sulphide derivatives in subjects with intact colon. Rao et al ${ }^{17}$ noted in a murine model that sulindac was transformed to its sulphone and sulphide metabolites mainly by intestinal bacteria and that these metabolites were absorbed by the colon and found in the blood. Consequently, in patients with only retained rectum after subtotal colectomy, a larger dose of active sulindac metabolite may be delivered locally to a smaller segment of colorectal mucosa than in patients with intact colon. Alternatively, Farmer et al have shown that previous colectomy decreases rectal epithelial proliferation in the retained rectum in FAP patients. ${ }^{18}$ Therefore, the effect of sulindac might be potentiated in operated patients because of changed mucosal characteristics. However, the mechanism by which sulindac regresses adenomas, through decreasing cell proliferation or increasing apoptosis, remains controversial. ${ }^{19}$

Surprisingly, baseline (initial) size and number of polyps was not a determinant of polyp regression. Several explanations for this finding are possible. Firstly, the dose of sulindac given (range 2.4 to $6.4 \mathrm{mg} / \mathrm{kg} /$ day) may have exceeded the threshold dose needed to produce polyp regression. In fact, in some study patients the longterm dose necessary to prevent polyp reappearance ranged between 1.3 to $2 \cdot 1 \mathrm{mg} / \mathrm{kg} /$ every other day (unpublished data). Also, in this patient group, maximum polyp size was $6 \mathrm{~mm}$ and polyps had the endoscopic appearance of tubular adenomas. Debinski et al, studying sulindac efficacy in the upper gastrointestinal tract of FAP patients, reported that small duodenal adenomas (less than or equal to $2 \mathrm{~mm}$ ) regressed while larger ones did not. ${ }^{20}$ Therefore, in a different study population with larger polyp size and more advanced histopathological characteristics (villous architecture, more severe dysplasia), baseline polyp number and size might be predictive factors of polyp regression.

Several clinical implications can be drawn from this analysis albeit with caution given the sample size of our study. Firstly, sulindac seems most effective for the treatment of adenomas in FAP patients with colectomy and ileorectal anastomosis, not for FAP patients without previous colon surgery. Thus, prophylactic colectomy will probably remain the primary treatment for patients with FAP. Secondly, large numbers of adenomas in the retained rectum should not be a deterrent to treatment. Caution should be applied, however, in those patients with rectal polyps of advanced histopathology or larger size than evaluated in this study. Also, although sulindac promotes polyp regression, efficacy in cancer prevention is another matter to be determined by longterm studies, especially in view of past case reports of rectal cancer in patients taking this drug. ${ }^{21} 22$ Consequently, sulindac treatment of patients with retained rectum should be coupled with vigilant endoscopic surveillance.

Supported in part by The Clayton Fund, The Praeventie Funds 28-2469 and NIH grants CA 53801 and CA 62924. Sulindac was kindly provided by Merck, Sharp and Dohme.

We thank Ms Linda $M$ Welch for secretarial support and D $\mathrm{J}$ Oosting for statistical advice.

1 Nonsteroidal anti-inflammatory agents. In: Mc Evoy G, ed. AHFS Drug Information. Bethesda MD: the American Society of Hospital Pharmacists, 1993: 1201-5.

2 Waddell WR, Loughry RW. Sulindac for polyposis of the colon. F Surg Oncol 1983; 24: 83-7.

3 Kinzler KW, Nilbert MC, Su LK, Vogelstein B, Bryan TM, Levy DB, et al. Identification of FAP locus genes from Levy DB, et al. Identification of FAP locus
chromosome 5q21. Science 1991; 253: 661-5.

4 Groden J, Thliveris A, Samowitz W, Carlson M. Gelbert L, Albertsen $\mathrm{H}$, et al. Identification and characterization of the familial adenomatous polyposis coli gene. Cell 1991; 66: 589-600.

5 Labayle D, Fischer D, Vielh P, Drouhin F, Pariente A Bories C, et al. Sulindac causes regression of rectal polyps in familial adenomatous polyposis. Gastroenterology 1991 ; 101: 635-9.

6 Giardiello FM, Hamilton SR, Krush AJ. Piantadosi S, Hylind LM, Celano P, et al. Treatment of colonic and rectal adenomas with sulindac in familial adenomatous rectal adenomas with sulindac in familial
polyposis. $N$ Engl $\mathcal{Y}$ Med 1993; 398: 1313-6.

7 Nugent KP, Farmer KCR, Spigelman AD, Williams DB, Phillips RKS. Randomized controlled clinical trial of sulindac on intestinal polyposis in FAP. Brf S Surg 1993; sulindac on 1618 .

8 Ahnen D, Alberts D, Hixson L, Paranka N, Burt R, Panukcu R. The sulfone metabolite of sulindac (FGN-1) inhibits rat colonic carcinogenesis but does not inhibit either prostaglandin synthesis or colonic proliferation. Gastroenterology 1995; 108: A444.

9 Nagase H, Miyoshi Y, Horii A, Aoki T, Ogawa M, Utsonomiya J, et al. Germ-line mutations of the APC gene in patients with familial adenomatous polyposis: screening of 150 unrelated patients. Am $\mathcal{f}$ Hum Genet 1992; 51: A39.

10 Powell SM, Petersen GM, Krush AJ, Booker SV, Jen J, Giardiello FM, et al. Molecular diagnosis of familial adenomatous polyposis. $N$ Engl f Med 1993; 329: 1982-7.

11 Miyoshi Y, Ando H, Nagase H, Nishisho I, Horii A, Niki Y, et al. Germ-line mutations of the APC gene in 53 familial adenomatous polyposis patients. Proc Natl Acad Sci 1992; 89: 4452-6.

12 Hucker HB, Stauffer SC, White SD, Rhodes RE, Arison BH, Umbenhauer ER, et al. Physiologic disposition and metabolic fate of a new anti-inflammatory agent, cis-r-Fluoro-2methyl-1-[p-(methylsulfinyl)-benzylidenyl]-indene-3-acetic acid in the rat, dog, rhesus monkey, and man. Drug Metabolism and Disposition 1973; 1: 721-36.

13 Duggan DE, Hooke KF, Risley EA, Shen TY, Van Arman CG. Identification of the biologically active form of sulindac. F Pharmacol Exp Ther 1977; 201: 8-13.

14 Hixson LJ, Alberts DS, Krutzsch M, Einsphar J, Brendel K, Gross PH, et al. Antiproliferative effect of nonsteroidal antiinflammatory drugs against human cancer cells. antinflammatory drugs against human cance

15 Ahnen D, Piazza G, Alberts D, Paranka N, Burt R, Pamukcu R. Sulindac sulfide and sulfone both inhibit the growth of colon cancer cell lines by inducing apoptosis. growth of colon cancer cell lines
Gastroenterology 1995; 108: A443.

16 Shen TY, Winter CA. Chemical and biological studies on indomethacin, sulindac and their analogs. Adv Drug Res 1977; 12: 89-245. 
17 Rao CV, Rivenson A, Simi B, Zang E, Kelloff G, Steele V, et al. Chemoprevention of colon carcinogenesis by sulindac, a nonsteroidal antiinflammatory agent. Cancer Res 1995; 55: 1464-72.

Res 1995; 55: 1464-72.
18 Farmer KCR, Phillips RKS. Colectomy and ileorectal anastomosis lowers rectal mucosal proliferation. Dis Colon Rectum 1993; 36: 167.

19 Pasricha PJ, Bedi A, O'Connor K, Rashid A, Akhtar AJ, Zahurak ML, et al. The effects of sulindac on colorectal proliferation and apoptosis in familial adenomatous polyposis. Gastroenterology 1995; 109: 994-8.

20 Debinski HS, Trojan J, Nugent KP, Spigelman AD, Phillips RKS. Effect of sulindac on small polyps in familial adenomatous polyposis. Lancet 1995; 345: 855-6.

21 Niv Y, Fraser GM. Adenocarcinoma in the rectal segment in familial polyposis coli is not prevented by sulindac therapy Gastroenterology 1994; 107: 854-7.

22 Thorson AG, Lynch HT, Smyrk TC. Rectal cancer in FAP patient after sulindac. Lancet 1994; 343: 180. 